\title{
INITIAL RESULTS OF LASER URETEROSCOPY TREATMENT FOR LITHIASIS OF THE UPPER URINARY TRACT AT ARISTIDE LE DANTEC HOSPITAL IN DAKAR (SENEGAL)
}

Oumar Gaye $^{* 1,2}$, Ngor Mack Thiam ${ }^{1,2}$, Youssef Bellamine ${ }^{1}$, Modou Ndiaye ${ }^{1}$, Boubacar Fall ${ }^{1}$, Yaya Sow ${ }^{1}$, Abdoulaye Ndiath ${ }^{1}$, Ousmane Sow ${ }^{1}$, Aboubacar Traoré ${ }^{1}$, Samba Thiapato Faye ${ }^{1}$, Ndiaga Seck Ndour ${ }^{1}$, Malick Diaw ${ }^{1}$, Babacar Sine ${ }^{1}$, Alioune Sarr ${ }^{1}$, Amath Thiam ${ }^{1}$, Cyrille Zé Ondo ${ }^{1}$, Babacar Diao ${ }^{1}$, Alain Khassim Ndoye ${ }^{1}$

${ }^{1}$ Urology-andrology department, Hopital Aristide Le Dantec, Dakar, Senegal

${ }^{2}$ Urology-andrology department, Hopital General Idrissa Pouye, Dakar, Senegal

Corresponding Author: Oumar Gaye: Urology-Andrology Department, Hôpital Aristide Le Dantec Dakar, Senegal. Email: oumargaye-uro@outlook.fr

Article Submitted: 24 January 2021. Article Accepted: 11 May 2021. Published: 12 July 2021.

\begin{abstract}
Background: In Africa, lithogenesis was initially considered rare and it was mostly caused by infections. Recent studies suggest that obesity, change in dietary habits (milk, dairy products) and hot climate can contribute to an increase of the condition in the region. Over the past decades, the management of upper urinary tract urolithiasis has evolved significantly with minimally invasive techniques. The challenge for sub-Saharan countries is related with the acquisition and the training for minimally invasive treatment. In fact, open surgery has less indications in the management of urolithiasis. The aim of this study is to evaluate the preliminary results of ureteroscopic laser treatment for upper urinary tract lithiasis in our hospital. Methods: This was a prospective, descriptive study realized between June 2016 and December 2018. The patients included were those who had ureteroscopic laser treatment for upper urinary tract lithiasis. The treatment was performed under general anesthesia by two surgeons. The studied parameters were: age, sex, patient medical history, comorbidities, renal function, cytobacteriological examination of urine, characteristics of lithiasis, intra and postoperative complications (using the Clavien-Dindo classification), ureteroscopic laser failures (frequency and causes). Success of treatment was defined by: the absence of a residual fragment at the renal and ureteral level or of a residual fragment $<4 \mathrm{~mm}$ at the renal level on the control imaging. Data analysis was done with IBM SPSS Statistic 23 software. Statistical significance was considered when $\mathrm{P}<0.05$.

Results: This study involved 43 patients. The mean age was 40.84 years \pm 15.33 years. The age group between 30 and 39 years was predominant. The sex ratio was 1.26. Nephritic colic was the circumstance of discovery in $93.02 \%$. The Uro-CT scan performed in all our patients, revealed kidney stones in $16.3 \%$ and ureteral stones in $83.7 \%$. The right side was the most involved in $55.8 \%$. The mean size of the stones was $12.2 \mathrm{~mm} \pm 4.89$ at the renal level and $12.05 \mathrm{~mm} \pm 5.54$ at the ureteral level. The semi-rigid ureteroscope was used in $88.37 \%$ and the flexible ureteroscope in $11.63 \%$. The lithiasis was visualized in $74.4 \%$ of cases. Laser fragmentation was performed in $69.77 \%$ of cases. A J stent was placed after $72.1 \%$ of cases. Pelvic ureteral stripping and pelvic ureteral aspiration were realized in one case each. Acute pyelonephritis (ANP) was observed in $25.6 \%$ of patients. There were $75 \%$ fragment free at postoperative control. Any factors associated with treatment failure were not found.
\end{abstract}




\section{INTRODUCTION}

The prevalence of urinary tract lithiasis has increased during the last decades, affecting nowadays about $9 \%$ of the adult population in the United States, with similar increasing rates in other developed countries. ${ }^{1,2}$ On the other hand, the epidemiological data for urinary tract lithiasis in most African and Asian countries are still under-reported because the prevalence and incidence rates are taken from hospital's data-centers only. ${ }^{3}$

In Africa, it was originally considered as a rare infectious disease. Recent studies suggest that obesity, diet changes, the increase of dairy products consumption and hot weather are risk factors of urinary tract lithiasis in the regions ${ }^{4,5}$ and they are the reasons for calcium lithiasis predominance in Africa like in western countries. ${ }^{6,7}$

The treatment choice for the management of the upper urinary tract lithiasis depends on the location, the size, the patient's preference, the available medical equipment and human resources of the hospital. ${ }^{8}$

During the course of the last decades, the management strategies of the upper urinary tract lithiasis has progressed a lot, especially with the advent of minimally invasive procedures. Despite that, open surgery is still the most commonly used method for the management of lithiasis in our regions. ${ }^{9,10}$ The challenge of the sub-Saharan African countries is the acquisition of the necessary equipment for minimally invasive procedures to manage upper urinary tract stones, but also the training of health care personnel in order to reduce complication rates. Therefore our department has endowed itself with a Semi Rigid Ureteroscope and a flexible ureteroscope with laser holmium as a mean of fragmentation.

Nevertheless, the acquisition of the ureteroscope, that allows a better management of the upper urinary tract lithiasis, requires a learning curve and the provision of consumables which is not easy to have in African regions.

Ureteroscopy is the procedure of addressing the kidney stones by introducing a ureteroscope through the bladder and extract the stone or break it using appropriate instruments. Nevertheless, the acquisition of a ureteroscope is essential for better treatment of our patients according to the latest guidelines, but also needs a learning curve.

The objective of this study was to evaluate the initial results of treating upper urinary tract stones by ureteroscopy in urology department of Hopital Aristide Le Dantec in Dakar (Senegal).

\section{MATERIAL AND METHODS}

It is a prospective study with a descriptive aim of a period from June 2016 to December 2018. Included patients where those who had ureteroscopy treatment using laser for upper urinary lithiasis treatment in the Hopital Aristide Le Dantec de Dakar. The used ureteroscopy was either flexible or semi rigid. The way of fragmentation used in our study is holmium YAG laser lithotripsy.

All our patients have had a contrast enhanced computed tomography (CT) in order to confirm the characteristics of the stone, AKA size, location, density and number. And to evaluate the upper urinary tract anatomy. A urinalysis was done for all the patients. The surgery was performed by two surgeons under general anesthesia. There were no stone retrieval devices nor were a stone control catheter and all of the ureteroscopies were performed on unprepared ureters.

The follow up was done by a CT to evaluate the efficacy of the ureteroscopy treatment. Success criteria were defined by the absence of stones in the kidney and the ureter or the absence of residual kidney stone $<4 \mathrm{~mm}$ on the control imaging.

The studied parameters were: age, sex, patients' history and comorbidity, renal function, urinalysis, the lithiasis characteristics, complications both intra and post-operative (according to Clavien-Dindo classification), the fails of ureteroscopy (rate and causes). The data analysis was done by IBM SPSS Statistic 2.0. The

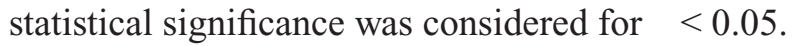

\section{RESULTS}

The total number of patients was 43. Year based repartition of the patients show that four patients were operated in 2016, 12 in 2017 and 27 in 2018. The average age of the patients was 40.84 with a standard deviation of 15.33. Extreme ages were 20 and 70 years old. The age group of 30-39 years was

J Endolum Endourol Vol 4(2):e13-e19; July 12, 2021.

This article is distributed under the terms of the Creative Commons AttributionNon Commercial 4.0 International License. (c) Gaye, et al. 
the majority with $30.2 \%$. Male patients were predominant at $55.8 \%$ with a sex ratio $\mathrm{M} / \mathrm{F}$ of 1.26 .Arterial Hypertension or diabetes were found in $9.4 \%$ of the patients. The combination of the two diseases was found in $4.7 \%$ of the patients. Obesity was found in $2.3 \%$ of our patients.

History of Extracorporeal Shock Wave Lithotripsy (ESWL) and ureteroscopy were found in $2.3 \%$ of the patients. Renal colic was the main symptom for 93.02\% of the patients. Hematuria and Lower Urinary Tract Symptoms (LUTS) were the main symptom for $4.65 \%$ of the patients. Creatinine was increased in $7.9 \%$ of the patients. Urinalysis was done for all of our patients and revealed a urinary tract infection for one patient and sterile pyuria for another patient.

A CT urogram has revealed kidney stones in $16.3 \%$ of the patients and ureteral stones in $83.7 \%$ of the patients. The right side was the most affected area with $55.8 \%$. We found one stone in $95.35 \%$ and two stones in $4.65 \%$ of the patients. The major location of the stone was the pelvic part of the ureter at $60.1 \%$ (Table 1). The average size of the stones was $12.2 \mathrm{~mm} \pm 4.89$ in the kidney and $12.05 \mathrm{~mm} \pm 5.54$ in the ureter (Tables 2 and 3).

Stone's density varied between 105 and $1561 \mathrm{HU}$ with a mean of $1020.9 \mathrm{HU} \pm 299.28$ stones with density between 1000 and $1500 \mathrm{HU}$ were predominant with

Table 1. Distribution of patients according to the topography of the stones.

\begin{tabular}{|l|c|c|}
\hline Topography & Number & Percentage (\%) \\
\hline LUMBAR & 9 & 20.9 \\
\hline ILIAC & 1 & 2.3 \\
\hline PELVIC & 26 & 60.1 \\
\hline CHALICE & 2 & 4.7 \\
\hline PYELIC & 5 & 11.6 \\
\hline Total & 43 & 100.0 \\
\hline
\end{tabular}

Table 2. Distribution of kidney stones according to their size.

\begin{tabular}{|l|c|c|}
\hline Size $(\mathbf{m m})$ & Number & Percentage (\%) \\
\hline$>20 \mathrm{~mm}$ & 0 & 0 \\
$10-20 \mathrm{~mm}$ & 3 & 42.9 \\
\hline$<10 \mathrm{~mm}$ & 4 & 57.1 \\
\hline Total & 7 & 100.0 \\
\hline
\end{tabular}

52.4\% (Table 4). Operating time varied between 50 and $200 \mathrm{~min}$ with a median of $96.19 \mathrm{~min}+/=29.87$. Semi rigid ureteroscope was used in $88.37 \%$ of the patients and flexible ureteroscope used in $11.63 \%$.

The stone was seen in $74.4 \%$ of the patients and $7 \%$ of the patient had impassable ureteral stenosis. Laser fragmentation was performed in $69.77 \%$ of the patients. Stone migration into the kidney was observed in $2.3 \%$ of the cases because of a high ureteral pressure, therefore it was not possible to break it. A double $\mathrm{J}$ stent was placed after 31 surgeries $(72.1 \%$ of the cases).

One patient had a perioperative ureteral stripping of the pelvic ureter due to forcing the progress of the ureteroscope, and one patient had a false passage in the pelvic ureter at the moment of placing the guide wire. Both patients were treated by a ureteral reimplantation surgery. The average hospitalization duration was $3.86 \pm 5.1$ days with extremes of 1 and 28 days. The double $\mathrm{J}$ stent was left in place for an average time of $28.66 \pm 10.89$ days with extremes of 8 and 60 days.

An acute pyelonephritis (ANP) was found in $25.6 \%$ of the patients. Urinalysis was done for all of those patients and showed a urinary tract infection due to a multi-drug resistant Pseudomonas Aeroginosa. A lumbar fossa pain was found in $7 \%$ of the patients and hematuria in $4.7 \%$ (Table 5).

We have found a link between the double J stent and the occurrence of ANP $(\mathrm{P}=0.019)$. During the

Table 3. Distribution of ureteral stones according to their size.

\begin{tabular}{|l|c|c|}
\hline Size $(\mathbf{m m})$ & Number & Percentage (\%) \\
\hline$<5 \mathrm{~mm}$ & 0 & 0 \\
$5-10 \mathrm{~mm}$ & 21 & 58.3 \\
\hline$>10 \mathrm{~mm}$ & 15 & 41.7 \\
\hline Total & 36 & 100.0 \\
\hline
\end{tabular}

Table 4. Distribution of calculations according to their density.

\begin{tabular}{|l|c|c|}
\hline Density (UH) & Number & Percentage (\%) \\
\hline$<1000$ & 8 & 38.1 \\
\hline $1000-1500$ & 11 & 52.4 \\
\hline$>1500$ & 2 & 9.5 \\
\hline Total & 21 & 100.0 \\
\hline
\end{tabular}


Initial results of laser ureteroscopy treatment

Table 5. Postoperative complications with the Clavien-Dindo classification.

\begin{tabular}{|l|c|c|}
\hline Type of complications (grade Clavien-Dindo) & Number & Percentage (\%) \\
\hline Acute pyelonephritis (grade II) & 11 & 25.6 \\
\hline Lumbar pain or nephretic colic (grade I) & 3 & 7 \\
\hline Haematuria (grade I) & 2 & 4.7 \\
\hline
\end{tabular}

Table 6. Determining factors of a residual fragment free.

\begin{tabular}{|l|c|c|}
\hline Stones characteristics & Success rate & P \\
\hline Location of stones & & \\
\hline Kidney & $66.7 \%$ & \\
\hline Ureteral & $77.8 \%$ & 0.6 \\
\hline Size of kidney stones & & \\
\hline$\leq 10 \mathrm{~mm}$ & $100 \%$ & \\
\hline $10<\mathrm{T} \leq 20 \mathrm{~mm}$ & $33.33 \%$ & 0.4 \\
\hline $\mathrm{T}>20 \mathrm{~mm}$ & & \\
\hline Size of ureteral stones & & \\
\hline$\leq 5 \mathrm{~mm}$ & & \\
\hline $5<\mathrm{T} \leq 10 \mathrm{~mm}$ & $100 \%$ & 0.08 \\
\hline$>10 \mathrm{~mm}$ & $55.56 \%$ & \\
\hline Operator experience & & \\
\hline Year 2016 & $100 \%$ & \\
\hline Year 2017 & $75 \%$ & 0.68 \\
\hline Year 2018 & $71.4 \%$ & \\
\hline
\end{tabular}

postoperative follow up, $75 \%$ of the patients were stone free of which $66.7 \%$ of them were kidney stone free and $77.8 \%$ of them were ureteral stone free. Further, $25 \%$ of the patients had residual fragments. Any associated factors of the treatment failure were not found during this study (Table 6).

\section{DISCUSSION}

We have had $95 \%$ of ureteroscopy performed as a first line treatment while Fall et al. ${ }^{11}$ and Padja et al. ${ }^{12}$ have had the ureteroscopy as a first line treatment in 62.3 and $50.32 \%$ of the cases, respectively. The high rate of first line ureteroscopy in our study can be explained by the non availability of ESWL and the percutaneous nephrolithotomy (PCNL) in our center during the study, but also by the recent acquisition of the ureteroscope. It is very important to have all the necessary equipment to manage upper urinary tract stones in the same hospital for better outcome.

Urinalysis performed for all of the patients revealed one case of urinary tract infection that was treated and one case of sterile pyuria. The ureteroscopy must be done only if urine is sterile (a negative urinalysis for less than a week and negative dipsticks the day of the surgery) or antibiotic treatment adjusted to the identified bacteria $48 \mathrm{~h}$ prior surgery. ${ }^{13,14}$ In our study, there was a significant interval between the urinalysis and the ureteroscopy. Even urine dipstick was not available.

The majority of kidney stones were located in the kidney pelvis at $71.4 \%$ and in the lower kidney calyx in $14.3 \%$ of the cases. For the ureteral stones, it was found that the majority of the stones were in the pelvic portion of the ureter at $72.2 \%$, the lumbar ureter at $25 \%$ and iliac ureter at $2.8 \%$.

The average size of the kidney stones was $12.2 \mathrm{~mm}$ \pm 4.89 ; the average size of ureteral stones was 12.05 $\mathrm{mm} \pm 5.54$. According to the American Urological Association (AUA) and the European Association of Urology (EAU). They recommend the ureteroscopy as the first line treatment of distal ureteral stones of more than $10 \mathrm{~mm}$. For stones less than $10 \mathrm{~mm}$ the AUA recommend ureteroscopy as first line treatment ${ }^{15,16}$ whereas ESWL has the same recommendation as ureteroscopy according to the EAU. ${ }^{17}$

According to the EAU and AUA, the ureteroscopy is the first line treatment for proximal ureteral stones no matter the size of the stone. ${ }^{15-17}$ According to the EAU and AUA, the first line treatment for the stones located in the kidney pelvis and high or middle renal calyx is ureteroscopy or ESWL if the stone is smaller than $20 \mathrm{~mm} .{ }^{15-17}$ The PCNL is a second option treatment of stones between 10 and $20 \mathrm{~mm}$ according to the EAU. ${ }^{17}$ The PCNL is the first option for kidney stone larger than $20 \mathrm{~mm}$ regardless the location of the stone. ${ }^{15-17}$

For lower pole renal stones that are smaller than $10 \mathrm{~mm}$, ureteroscopy or ESWL can be performed. For stones between 10 and $20 \mathrm{~mm}$, ureteroscopy and PCNL can be performed. ${ }^{15-17}$ 
The stones with a density of more than $1000 \mathrm{HU}$ were predominant at $61.9 \%$ of the cases. Padja ${ }^{12}$ also found that the majority of the patients have a stone density higher than $1000 \mathrm{HU}$ at $80.65 \%$. This low rate found in the study may be explained by the unavailability of ESWL in the hospital.

In fact, the stones having characteristics making them likely to have a treatment failure with ESWL (higher density than $1000 \mathrm{HU}$, smooth surface, cystine, calcium oxalate monohydrate) are good indications for ureteroscopy. ${ }^{18}$

All of the patients were operated under general anesthesia and had antibiotic prophylaxis with third generation cephalosporins. In some specific cases, however, patients underwent ureteroscopy under locoregional anesthesia and had similar results to those who were under general anesthesia. Pain level was the same as a cystoscopy. ${ }^{19}$ This type of anesthesia could be well adapted to our situation where medical staff is not sufficient. Antibiotic prophylaxis with second and third generation cephalosporins is essential to reduce the risk of infections. ${ }^{20}$

The average operating time was $96.19 \mathrm{~min} \pm 29.87$ min. Padja et al. had an average operating time of $73 \mathrm{~min} \pm 25 \mathrm{~min}$. Operating time is very fluctuating in literature but $60 \mathrm{~min}$ is usually enough for the fragmentation of a stone of $10 \mathrm{~mm} .^{12}$ The operating time in this study, that is more than the average can be explained by the learning curve.

We used the semi rigid ureteroscope for $88.37 \%$ of our patients and flexible ureteroscope for $11.63 \%$ of the patients. Stone location was the determining factor to choose between the types of ureteroscopy. Flexible ureteroscopy is more interesting for the treatment of renal pelvis and renal calyx stones, and lumbar ureteral stones. For distal ureteral stones however, rigid or semi rigid ureteroscopy in the best treatment option. However, it is mandatory to have both flexible and semi rigid ureteroscopes available at the same time as a ureteral stone can migrate into a renal calyx, and specifically to the lower renal calyx that requires the flexible ureteroscope to be treated. ${ }^{21}$

An impossible to overcome stenosis of the ureter was found in three patients (7\%). A double J stent was placed in two cases and one case was converted to open surgery. In fact, for these cases, it was considered better to place a double J stent and postpone the ureteroscopy or do an ESWL with the double $\mathrm{J}$ stent. ${ }^{22}$ A ureter preparation for those patients could have helped avoid that. However, it is difficult to do that in the context of this study, due to the limited number of specialist doctors and high number of patients.

The fragmentation was performed for 69.77 of the patients. The fragmentation rate was higher in studies done by Niang et al. ${ }^{21}$ and Wakrim et al. ${ }^{23}$ who had a $95.6 \%$ fragmentation rate. This low fragmentation rate can be explained by the fact that some stones were not visible during ureteroscopy and tight ureteral stenosis.

A better CT-urogram interpretation and an abdominal $\mathrm{X}$-ray 1 day prior surgery wound have increased the fragmentation rate. The provision of a stone retrieval basket and high qualty irrigation equipment could have allowed to avoid stone migration.

A double $\mathrm{J}$ stent was placed for $72.1 \%$ of the patients. Upper urinary tract drainage is not systematic and depends on the conditions and the difficulties encountered during the ureteroscopy. A non traumatic ureteroscopy, short operation time, without ureteral dilation nor residual fragments do not justify a drainage. On the other hand, in case of a ureteral trauma or the presence of residual fragments impose upper urinary tract drainage by a double $\mathrm{J}$ stent for 8 to 15 days. ${ }^{18}$

It is found that there exists a relation between the placement of the double $J$ Stent and the occurrence of ANP $(\mathrm{P}=0.019)$. However, Djaladat et al. did not find a relation between the hospitalization time and infection rate and rehospitalization. ${ }^{24}$ One case of a ureteral stripping in the pelvic ureter $(2.33 \%)$ due to a forced progression of the ureteral access stealth. We had one case of false route in the pelvic ureter $(2.33 \%)$ while placing the wire guide in the ureter. Both of these complications were treated by ureteral Ureteral Reimplantation. A major complication risk (perforation or avulsion) is around $1 \%$. The risk of a ureteral avulsion is around $0.2 \%$. Risk factors are: a ureteroscope bigger than $11 \mathrm{Fr}$, the absence of the dilation of the meatus, a forced progression and the attempt to extract the stone using the kidney stone basket extraction in one-piece. ${ }^{25}$ There are no recommendations for open surgery but it is still often necessary. ${ }^{26}$

An ANP was found in $25.6 \%$ of the patients. Urinalysis done for those patients revealed a urinary tract 
infection due to a multidrug resistant pseudomonas aeruginosa. The ablation of the double J stent was performed and double antibiotic treatment (ceftriaxone $2 \mathrm{~g}+$ amikacine $15 \mathrm{mg} / \mathrm{kg}$ ) was prescribed to all of those patients. Padja et al., ${ }^{12}$ Fall et al., ${ }^{11}$ and Niang et al. ${ }^{21}$ have had post ureteroscopy ANP rates of 6.02, 5.75 and $5.5 \%$ respectively.

This high rate of ANP found in our study is due to a nosocomial infection because the authors have found the same bacteria in all the infected patients, and they all had a placement of a double J stent. A better training of the staff in terms of instruments sterilization and urinalysis performed in less than a week before surgery would have allowed reduce the post-operative infections.

The average duration of hospitalization was 3.86 \pm 5.1 days with extremes of 1 and 28 days. Padja et al., ${ }^{12}$ Niang et al. ${ }^{21}$ and Ibrahim et al. ${ }^{27}$ had an average hospitalization time of 2 and 2.54 days, respectively. The high hospitalization time in this study is due to the long hospitalization of one patient who underwent a reimplantation surgery and had to stay for 28 days at the hospital after having a vesico-cutaneous fistula as a complication. Usually, the hospital stay after ureteroscopy is 1 to 2 days. The ureteroscopy can be performed as outpatient surgery without the increase of rate of complications and with similar outcome to ureteroscopy with hospitalization. ${ }^{28}$

This study found $75 \%$ of the patients to be stonefree after surgery. These results are similar to the study done by Fall et al. ${ }^{11}$ and Padja et al. ${ }^{12}$ who had stone free results of 71.1 and $78.91 \%$, respectively. De la rosette et al. had a stone-free outcome of $85.6 \%$. Any factors of failure of the treatment were not found. Padja et al. ${ }^{12}$ also did not find any factors of failure. Whereas Fall et al. ${ }^{11}$ found out that the surgeon's experience can significantly modify the outcome of the surgery, and Ben saddik ${ }^{29}$ revealed that there is a significant outcome difference due to the size of the kidney stone.

\section{CONCLUSION}

Laser ureteroscopy is an effective technique for the management of upper urinary tract lithiasis. It needs a perfect knowhow of the technique, the provision of sufficient human recourses and adequate instruments in order to reduce complication rates. The better organization of our department and acquisition of consumables will help improve our results.

\section{REFERENCES}

1. Scales CD Jr, Smith AC, Hanley JM, Saigal CS. Prevalence of kidney stones in the United States. Eur Urol. 2012;62:160. http://dx.doi.org/10.1016/j. eururo.2012.03.052

2. Pinduli I, Spivacow R, Del Valle E, Vidal S, Negri AL, Previgliano H, et al. Prevalence of urolithiasis in the autonomous city of Buenos Aires, Argentina. Urol Res. 2006;34:8. http://dx.doi.org/10.1007/s00240-005-0003-7

3. Rizvi SA, Naqvi SA, Hussain Z, Hashmi A, Hussain M, Zafar MN, et al. The management of stone disease. BJU Int. 2002;89:62-8. http://dx.doi. org/10.1046/j.1465-5101.2001.134.x

4. Hounnasso PP, Avakoudjo JD, Paré AK, Brahima K, Ouattara A, Agounkpé MM, et al. Symptomatic urinary lithiasis: Epidemiology and management at urology department of university hospital of cotonou. Open J Urol. 2015;5(2):7-12. http://dx.doi.org/10.4236/ oju.2015.52002

5. Rimtebaye K, Sillong FD, Tashkand AZ, Kaboro M, Niang L, Gueye SM. Urolithiasis: Diagnostic and therapeutic aspects in urology department of n'djamena in chad. Open J Urol. 2015;5(11):199-206. http:// dx.doi.org/10.4236/oju.2015.511032

6. Wathigo FK, Hayombe A, Maina D. Urolithiasis analysis in a multiethnic population at a tertiary hospital in Nairobi, Kenya. BMC Res Notes. 2017;10(158):1-5. http://dx.doi.org/10.1186/s13104-017-2474-3

7. Bouatia M, Benramdane L, Idrissi MO, Draoui M. An epidemiological study on the composition of urinary stones in Morocco in relation to age and sex. Afr J Urol. 2015;21(3):194-7. http://dx.doi.org/10.1016/j. afju.2015.02.006

8. Zumstein V, Betschart P, Abt D, Schmid HP, Panje CM, Putora PM. Surgical management of urolithiasis-A systematic analysis of available guidelines. BMC Urol. 2018;18(25):1-8. http://dx.doi.org/10.1186/ s12894-018-0332-9

9. Diallo Y, Kouka SC, Kane R, et al. Lithiase du haut appareil urinaire: Aspects épidémiologiques, cliniques et thérapeutiques dans la région de Thiès, Sénégal. Rev Méd Madag. 2015;5(1):520-5.

10. Kambou T, Traore AC, Zango B, Bonkoungou B, Ouattara T, Sanou A. Lithiase du haut appareil urinaire

J Endolum Endourol Vol 4(2):e13-e19; July 12, 2021.

This article is distributed under the terms of the Creative Commons AttributionNon Commercial 4.0 International License. (C) Gaye, et al. 
au Centre Hospitalier Universitaire Sanou Souro de Bobo-Dioulasso (Burkina Faso): Aspects épidémiologiques, cliniques et thérapeutiques: A propos de 110. Afr J Urol. 2005;11(1):55-60.

11. Fall B, Mouracade P, Bergerat S, Saussine C. L'urétéroscopie souple-laser dans le traitement des calculs du rein et de l'uretère: indications, morbidité et résultats. Prog Urol. 2014 Oct;24(12): 771-6. http:// dx.doi.org/10.1016/j.purol.2014.06.007

12. Padja E, Ibarra VA, Lmezguidi K, Janane A, Ghadouane M, Ameur A, et al. Urétéroscopie souple laser dans le traitement des calculs du haut appareil urinaire: résultats à propos de 166 interventions. Pan Afr Med J. 2015;22:13. http://dx.doi.org/10.11604/ pamj.2015.22.13.7591

13. Conort P, Doré B, Saussine C. Prise en charge urologique des calculs rénaux et urétéraux de l'adulte. Prog Urol. 2004;14:1096-102.

14. Knopf HJ, Graff HJ, Schulze H. Perioperative antibiotic prophylaxis in ureteroscopic stone removal. Eur Urol. 2003;44:115-18. http://dx.doi.org/10.1016/ S0302-2838(03)00189-1

15. Assimos D, Krambeck A, Miller NL, et al. Surgical management of stones: American Urological Association/Endourological Society guideline, part I. J Urol. 2016;196:1153. http://dx.doi.org/10.1016/j. juro.2016.05.090

16. Assimos D, Krambeck A, Miller NL, et al. Surgical management of stones: American Urological Association/Endourological Society guideline, part II. J Urol. 2016;196:1161. http://dx.doi.org/10.1016/j. juro.2016.05.091

17. T€urk C, Petrik A, Sarica K, et al. EAU guidelines on interventional treatment for urolithiasis. Eur Urol. 2016;69:475. http://dx.doi.org/10.1016/j. eururo.2015.07.041

18. Lechevallier E, Saussine C, Traxer O. Urétéroscopie pour calcul du haut appareil urinaire. Prog Urol. 2008 Dec;18(12):912-16. http://dx.doi.org/10.1016/j. purol.2008.09.022

19. Park HK, Paick SH, Oh SJ, Kim HH. Ureteroscopic lithotripsy under local anesthesia: Analysis of the effectiveness and patient tolerability. Eur Urol. 2004;45:670-3. http:// dx.doi.org/10.1016/j.eururo.2004.01.003

20. Niang L, Pare AK, Ndoye M, Samassékou A, Avakoudjo DJG, Agounkpé MM, et al. Urétéroscopie rétrograde: Expérience de l'hôpital général de Grand-Yoff. Afr J Urol. 2016;22(2):110-14. http://dx.doi.org/10.1016/j. afju.2016.01.002

21. Deliveliotis C, Chrisofos M, Albanis S, Serafetinides E, Varkarakis J, Protogerou V. Management and follow-up of impacted ureteral stones. Urol Int. 2003;70:269-72. http://dx.doi.org/10.1159/000070133

22. Wakrim B. Place de l'urétéroscopie dans la prise de la charge de la lithiase urétérale. Marrakech; 2008.

23. Djaladat H, Tajik P, Payandemehr P, Alehashemi S. Ureteral catheterization in uncomplicated ureterolithotripsy: A randomized, controlled trial. Eur Urol. 2007;52:836-41. http://dx.doi.org/10.1016/j. eururo.2007.01.042

24. Alapont JM, Broseta E, Oliver F, Pontones JL, Boronat F, Jiménez-Cruz JF. Ureteral avulsion as a complication of ureteroscopy. Int Braz J Urol. 2003;29:18-22. http://dx.doi.org/10.1590/S1677-55382003000100004

25. Jungers P, Joly D, Blanchard A, et al. Lithiases rénales héréditaires monogéniques: récents acquis diagnostiques et thérapeutiques. Néphrol Thér. 2008;4:231-55. http:// dx.doi.org/10.1016/j.nephro.2007.12.005

26. Ibrahim AK. Reporting ureteroscopy complications using the modified clavien classification system. J Urol Ann. 2015 Jan-Mar;7(1):53-7. http://dx.doi. org/10.4103/0974-7796.148611

27. Moyano Calvo JL, Huesa Martinez I, Ramirez Mendoza A, Di ivalos Casanova G, Aparcero Rodriguez E, Morales Lopez A, et al. Ambulatory ureteroscopy and pneumatic lithotripsy. Our experience after 1803 ureteral stones. Arch Esp Urol. 2004;57:539-44.

28. Ben Saddik MA, Al-Qahtani Sejiny S, Ndoye M, Gil-diez-deMedina S, Merlet B, Thomas A, et al. Urétéroscopie souple dans le traitement des calculs du rein de 2 à $3 \mathrm{~cm}$. Prog Urol. 2011;21:327-32. http:// dx.doi.org/10.1016/j.purol.2010.07.012 